\title{
Programmed Cell Death Pathways in the Pathogenesis of Idiopathic Inflammatory Myopathies
}

\begin{abstract}
Jia Shi ${ }^{1,2}$, Mingwei Tang ${ }^{1,2}$, Shuang Zhou ${ }^{1,2}$, Dong $X u^{1,2}$, Jiuliang Zhao ${ }^{1,2}$, Chanyuan Wu ${ }^{1,2 *}$, Qian Wang ${ }^{1,2 *}$, Xinping Tian ${ }^{1,2}$, Mengtao $\mathrm{Li}^{1,2}$ and Xiaofeng Zeng ${ }^{1,2}$

${ }_{1}^{1}$ Department of Rheumatology and Clinical Immunology, Peking Union Medical College Hospital, Peking Union Medical College \& Chinese Academy of Medical Sciences, Key Laboratory of Rheumatology \& Clinical Immunology, Ministry of Education, Beijing, China, ${ }^{2}$ National Clinical Research Center for Dermatologic and Immunologic Diseases (NCRC-DID), Ministry of Science \& Technology, Beijing, China
\end{abstract}

Idiopathic inflammatory myopathy (IIM) is a heterogeneous group of acquired, autoimmune muscle diseases characterized by muscle inflammation and extramuscular involvements. Present literatures have revealed that dysregulated cell death in combination with impaired elimination of dead cells contribute to the release of autoantigens, damage-associated molecular patterns (DAMPs) and inflammatory cytokines, and result in immune responses and tissue damages in autoimmune diseases, including IIMs. This review summarizes the roles of various forms of programmed cell death pathways in the pathogenesis of IIMs and provides evidence for potential therapeutic targets.

Keywords: idiopathic inflammatory myopathy (IIM), programmed cell death (PCD), apoptosis, autophagy, NETosis, pyroptosis

\section{HIGHLIGHTS}

- Dysregulated cell death in combination with impaired elimination of dead cells, get involved in the pathogenesis of IIMs.

- Programmed necrosis, such as NETosis and pyroptosis, seems to play a more important role in the pathogenesis of IIMs, which contribute to the release of autoantigens, damage-associated molecular patterns and proinflammatory cytokines.

- The mechanisms of PCD seem to vary among different subtypes of IIM and require even more precise studies according to different myositis-specific antibodies.

Received: 26 September 2021 Accepted: 08 November 2021 Published: 24 November 2021

Citation:

Shi J, Tang M, Zhou S, Xu D, Zhao J,

Wu C, Wang Q, Tian X, Li M and Zeng X (2021) Programmed Cell Death

Pathways in the Pathogenesis of Idiopathic Inflammatory Myopathies.

Front. Immunol. 12:783616 doi: 10.3389/fimmu.2021.783616

\section{INTRODUCTION}

Idiopathic inflammatory myopathy (IIM) is a heterogeneous group of acquired, autoimmune muscle diseases characterized by production of a spectrum of autoantibodies [including myositis-specific autoantibodies (MSAs) and myositis-associated autoantibodies (MAAs)], aberrant regulation of inflammatory responses, and tissue damage of different organs. The most common subtypes of IIMs are represented by dermatomyositis (DM), polymyositis (PM), inclusion body myositis (IBM), 
immune-mediated necrotising myopathy (IMNM), antisynthetase syndrome (ASSD) and overlap myositis (1). The exact pathogenesis of IIMs has not been fully elucidated, but was reported to be related to genetic and environmental factors, abnormal immune responses and non-immune responses (2).

Almost exclusively found in IIM patients, MSAs include antisynthetase autoantibodies (ARS), anti-Mi-2, anti-signal recognition particle (SRP), anti-melanoma differentiationassociated gene 5 (MDA5), anti-nuclear matrix protein 2 (NXP2), anti-transcription intermediary factor $1 \gamma$ (TIF1 $\gamma)$, antismall ubiquitin-like modifier activating enzyme (SAE), and anti- 3Hydroxy-3-methylglutaryl CoA reductase (HMGCR). Their targeting antigens are ubiquitously expressed and are involved in key cellular processes, including gene expression and developmental regulation (3), but how these intracellular components get exposed to the immune system, elicit immune responses and lead to the generation of MSAs, remain unclear. Besides, overexpressed cytokines have been found in the serum and diseased muscle tissues of IIM patients. For instance, the level of type I interferon (IFN) is increased significantly in the muscles of DM patients (4). Therefore, it is reasonable to speculate that abnormal cell death may play a role in the pathogenesis of IIMs. Currently, accumulating evidences have revealed that excessive cell death in combination with impaired elimination of dead cells and debris contribute to the release of autoantigens, danger-associated molecular patterns (DAMPs) and proinflammatory cytokines, and consequently, the over-activated immune and inflammatory responses in IIMs (5). According to functional aspects, cell death can be classified into programmed cell death (PCD) and accidental cell death (ACD) (6). Used to be mistaken for the synonyms of apoptosis, essentially PCD also incorporates autophagy-dependent cell death and programmed necrosis (7) (such as NETosis, pyroptosis, ferroptosis and necroptosis) (Figure 1).

In this review, we focus on recent research progression of PCD pathways in the pathogenesis and progression of IIMs to provide evidence for potential therapeutic targets.

\section{APOPTOSIS AND SECONDARY NECROSIS AFTER APOPTOSIS}

Apoptosis is a genetically-controlled non-lytic cell death pathway, designed to dismantle and remove senescent and injured cells, thereby preventing unwanted inflammation during development, homeostasis, and infection (8). The main features of apoptosis are cytoplasmic shrinkage, membrane blebbing, chromatin condensation and nuclear fragmentation (6). Two distinct apoptotic signaling pathways, intrinsic (also called the mitochondrial pathway) and extrinsic pathways, have been defined. The extrinsic pathway can be triggered by death factors of the tumor necrosis factor (TNF) family [including Fas ligand (CD95L, FasL), TNF- $\alpha$, and TNF-related apoptosisinducing ligand (TRAIL)], while the intrinsic pathway is activated by microenvironmental perturbations including endoplasmic reticulum stress (ERS), reactive oxygen species (ROS), or lack of nutrient support (9). Mitochondrial outer membrane permeabilization (MOMP) is the critical and irreversible step for intrinsic apoptosis, which is regulated by Bcl-2 family members (10). Both apoptotic pathways are mediated by specific sets of caspases which act in cascades, among which caspase- 8 and caspase- 9 being the initiators for the extrinsic pathway and the intrinsic pathway, respectively. Once activated, either caspase- 8 or caspase- 9 activates executioner caspase- 3 and caspase- 7 and leads to apoptosis of the doomed cell (11). Macrophages engulf these dead cells in a process called efferocytosis by recognizing "find me" signals [such as ATP, UTP, sphingosine-1-phosphate (S1P) and CX3CL1 (fractalkine)] and "eat me" molecules (such as phosphatidylserine, oxidized LDL-like molecules and C1qbound serum proteins) released by these cells (10). However, when apoptotic cells are not engulfed efficiently and timely, they undergo secondary necrosis, which is featured with permeabilization of plasma membranes and release of intracellular contents that may activate the immune system (7).

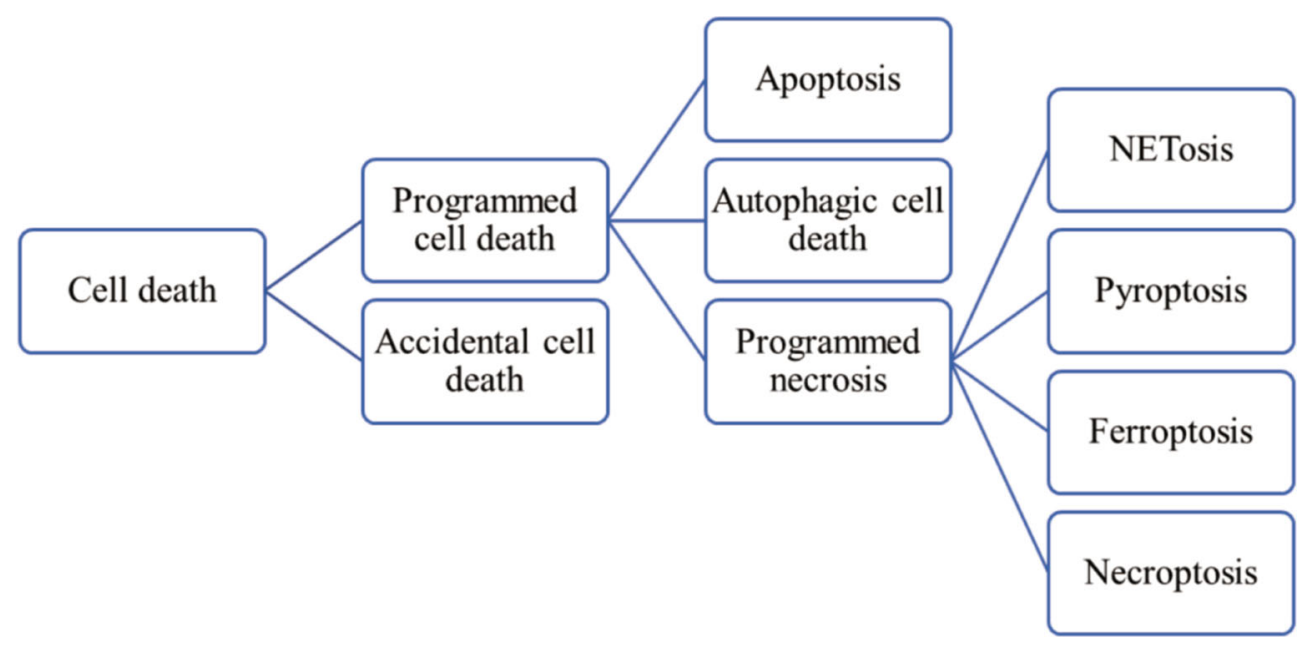

FIGURE 1 | Classification of cell death. 
Peripheral $\mathrm{T}$ cell lymphopenia has been reported in some patients with DM, which is associated with the increased Fasmediated apoptosis of $\mathrm{T}$ cells. The overexpression of retinoic acid-inducible gene I (RIG-I) could induce T cell apoptosis, but the mechanism is far from clear (12). Also, lymphopenia may be resulted from the decreased autophagy, which is discussed later below (13). Noteworthily, in patients of IIM, T cells infiltrating in the muscles are dominated by $\mathrm{CD} 28^{\text {null }} \mathrm{T}$ cells, partly due to chronic antigenic stimulation (14), which show an increased percentage in peripheral blood mononuclear cells (PBMCs) as well (15-18). CD28 null $\mathrm{T}$ cells infiltrating in IIM muscles are generally regarded as terminally differentiated and apoptosis resistant with properties of replicative senescence $(16,17,19$, 20 ), because of decreased expression of Fas (21), and increased expression of antiapoptotic molecule $\mathrm{Bcl}-2$ (22), Bcl- $\mathrm{x}_{1}$ and cyclin-dependent kinase inhibitors p16 and p57 (20), upregulation of the phosphoinositide 3-kinase pathway (23) (which inhibits Fas-initiated apoptosis), and upregulation of various inhibitory natural killer cell receptors (iNKRs) (24) (such as CD94/NKG2A). CD28 ${ }^{\text {null }} \mathrm{T}$ cells are not capable of costimulatory interaction with CD80 and CD86, but this does not represent a global loss of costimulatory receptor expression. The upregulation of alternative costimulatory molecules, such as inducible costimulator (ICOS), CD134 and CD137, has been reported in CD28 $8^{\text {null }} \mathrm{T}$ cells after CD3 ligation (25). Moreover, this T-cell phenotype is suggested to be treatment-resistant for its persistence in muscle tissue after high doses of glucocorticoids and other immunosuppressive treatment, which is correlated with a poor clinical response (17), and could be due to a significant loss of glucocorticoid receptors (GCRs) (26). Therefore, CD28 ${ }^{\text {null }} \mathrm{T}$ cells are an emerging target of interest for treatment in refractory myositis patients. Existing drugs that could downregulate $\mathrm{T}$ cells include calcineurin inhibitors (e.g., tacrolimus and cyclosporine) and abatacept. Calcineurin inhibitors could prevent calcineurin from dephosphorylating nuclear factor of activated $\mathrm{T}$ cell (NFAT) proteins and then repress transcription of IL-2, and thereby restraining the differentiation and survival of $\mathrm{T}$ cells (27). A single-arm prospective clinical trial revealed that initial combination treatment with tacrolimus and GCs could improve short-term mortality of PM/DM-ILD patients with satisfactory safety (28). Abatacept, an agonist of cytotoxic T-lymphocyte antigen-4 (CTLA-4), could interfere with the activation of $\mathrm{T}$ cells by binding CD80/CD86 on the surface of antigen-presenting cells (APCs). A phase IIb, delayed-start clinical trial of abatacept was conducted in 20 refractory DM/PM patients. Decreased disease activity was observed in $42 \%$ of the patients, as well as upregulated Foxp $3^{+}$regulatory $\mathrm{T}$ cells in repeated muscle biopsies (29). There is a phase III, randomized, double-blind trial underway to further evaluate abatacept for myositis treatment (Clinical Trial Identifier NCT02971683).

In PM, CD28 ${ }^{\text {null }} \mathrm{T}$ cells have been demonstrated to be able to exert direct cytotoxicity towards myocytes by polarizing perforin and secreting granzyme $\mathrm{B}$, and indirectly contribute to myotube cell death by releasing proinflammatory cytokines IFN- $\gamma$ and TNF which could induce surface expression of MHC, rendering the myocytes more sensitive to cytotoxic attacks (30). An in vitro study also identified that culturing myoblasts with IFN- $\gamma$ or TNF alone could upregulate inflammation related transcription factors (NF- $\kappa \mathrm{B}$, nuclear factor- $\kappa \mathrm{B}$ ) and induce apoptosis (31), implying that extracellular inflammation induces further inflammatory changes and forms a sustained loop of inflammation leading to cell death. One study on IBM showed that the combination of $\beta$-amyloid (A $\beta$ ) with IFN- $\gamma$ stimulating pathogenic $\mathrm{NO}_{2}^{-}$production via induction of iNOS gene expression could induce apoptosis of myocytes (32), while the other found $A \beta$ alone is sufficient for myofiber apoptosis (33). In hereditary IBM, mutations in gene GNE could lead to impaired apoptotic signaling, thus causing degenerative process and muscle loss (34). Moreover, the expressions of Fas and cytoplasmic caspase- 8 and -3 of myocytes could be upregulated by proinflammatory cytokines as well (35), but whether myocytes apoptosis mediated by Fas/FasL interaction is involved in the pathogenesis of IIM is controversial. Fas expression in muscle fibers has been reported with very different frequencies (36-39). The presence of myocytes with TUNEL positive nuclei has been reported in IIMs but was very rare. As for this phenomenon, some researchers consider that the frequencies of apoptosis are too low to prove the relevance to pathopoiesis, while others believe that it is attributed to the prompt efferocytosis. These rare apoptotic myocytes were surrounded by $\mathrm{CD}^{+} \mathrm{T}$ cells and granzyme $\mathrm{B}^{+}$cells with absence of Fas and upregulating MHC-I, favouring a cytotoxic mode of apoptosis induction rather than a Fas-mediated mechanism (37), which is in line with an earlier study, suggesting Fas expression may be attributed to the new gene expression in regenerating fibers (38). The resistance of myocytes to apoptosis is attributable to anti-apoptotic intracellular proteins, such as Bcl-2 (36), FLICE (Fas-associated death domain-like IL-1-converting enzyme)-inhibitory protein (FLIP) (40) and human IAP-like protein (hILP) (41). Notably, in contrast with previous study, Bcl-2 has been reported to exhibit lower expression in diseased muscle compared with normal muscle (39). Therefore, the mode of myocyte death needs to be further investigated.

Nevertheless, some therapeutic strategies regarding apoptosis have been identified. Resistance exercise (RE) has been demonstrated to reduce $A \beta$ accumulation in chloroquine (CQ)induced rat model of IBM, thus inhibiting mitochondrial-mediated apoptosis of myofibers and improving mitochondrial function through increased mitochondrial biogenesis, upregulated mitophagy, and activated sirtuin 3 signaling (42). Alemtuzumab, a recombinant DNA-derived humanized monoclonal antibody targeting CD52, was also beneficial for IBM patients, as it lowered the count of peripheral and endomysial $T$ cells with reduced mRNA expression of Fas (43). It could enhance apoptosis in B cells by upregulating the expression of caspase- 8 and caspase- 3 in chronic lymphocytic leukemia as well (44), which may provide a valuable reference for IIM. Besides, pro-senescent interventions consisting of exercise and AMP-activated protein kinase (AMPK) activation induced apoptosis of fibro-adipogenic progenitors (FAP) and promoted muscle regeneration in a murine chronic inflammatory 
myopathy (CIM) model, suggesting that the FAP-targeted intervention may be therapeutic (45). In PM/DM, expressions of cathepsin $\mathrm{B}(\mathrm{CB})$ and calpain are increased in muscle and lung tissues, which promotes cell apoptosis and inflammation. Calpeptin (calpain inhibitor) ameliorated morphological changes of apoptosis in IFN- $\gamma$ or TNF- $\alpha$ treated myoblasts through both mitochondrial pathway and ERS pathway $(31,46)$. Also, the administration of CA$074 \mathrm{Me}$, a specific inhibitor of $\mathrm{CB}$, could attenuate apoptosis of myocytes and lung epithelial cells, and reduce lung interstitial inflammation and fibrosis in the guinea-pig model of PM $(47,48)$.

\section{AUTOPHAGY AND AUTOPHAGIC CELL DEATH}

Autophagy is a highly conserved catabolic and homeostatic process by which subcellular components are secluded and degraded via lysosomes under stress conditions, such as ERS, nutritional deprivation, mitochondrial injury, and inflammation (49). It is featured with vacuolization of the cytoplasm and accumulation of double-membraned vacuoles (i.e., autophagosome) in morphology. According to the modes of cargo transferring to the lysosome, autophagy is classified as macroautophagy, microautophagy and chaperone-mediated autophagy (CMA). In addition to elimination of intracellular aggregates and damaged organelles, autophagy plays crucial roles in inflammation and immune-system function, mediating cytoprotective rather than cytotoxic effects. The interplay between autophagy and cytokines is fundamental to modulate inflammatory as well as immune responses. For instance, TNF- $\alpha$ can induce autophagy and in turn, whether autophagy up- or down-regulates TNF- $\alpha$ formation depends on the cellular context (50). Autophagic cell death is a type of PCD that relies upon the autophagic machinery or constituents thereof, with massive autophagic vacuolization of the cytoplasm but without chromatin condensation (51).

Most IIM studies with regard to autophagy focus on IBM. Rare missense variants in autophagy-related genes, such as VCP, HNRPA2B1, BAG3, SQSTM1, FLNC and ZASP have been identified to occur at a higher frequency in IBM patients than in control populations (52). VCP mutations could result in defective myotube formation, increased apoptosis and increased autophagy (53). Moreover, a study based on whole exome sequencing (WES) identified missense variants in FYCO1, which encodes for an LC3binding protein accumulating at rimmed vacuoles and is implicated in microtubule transport of autophagosomes, were statistically enriched in IBM patients (54). Collectively, these findings revealed a strong tie between IBM susceptibility and autophagy. In IBM muscle tissues, increased formation of vacuolar autophagosomes has been identified along with massive protein aggregation, as indicated by increased levels of p62, LC3, mTORmediated phosphorylation of p70SK, $\alpha$-synuclein and TDP-43 (5557). These markers could be ancillary tools to differentiate IBM from other IIMs (56). In the inflammatory milieu in muscle, the upregulated proinflammatory cytokines, such as IL-1 $\beta$ (58), TNFlike weak inducer of apoptosis (TWEAK) (59) and TRAIL (60), get involved in stimulating autophagic cell death. Besides, the overexpression of MHC-II in inflamed muscle fibers, partly on account of the increased cytokine TNF- $\alpha$, could induce autophagy and interact with IFN- $\gamma$ to translocate intracellular MHC-II to the myocyte surface further (61). Also, defective autophagy could drive increased MHC-I expression because of the weakening ability of MHC-I internalization for degradation (62). All the evidence revealed that dysregulated autophagy might contribute to antigen presentation for MHC-I and II, and maintain the inflammatory response in a vicious circle (63).

The overmuch autophagy reflected by overexpression of autophagic proteins in muscle, and impaired protein degradation, contributing importantly to consequent accumulation of multiprotein aggregates, are key factors in the myofiber degeneration characteristic of IBM $(55,64,65)$. Specially, the accumulation of amyloid- $\beta 42$ oligomers, could cause reduction in muscular peak force and amplitude of $\mathrm{Ca}^{2+}$ transients in mouse models of IBM (66), suggesting that their cytotoxicity contribute importantly to IBM pathogenic cascade. Cylindromatosis (CYLD), a deubiquitinating enzyme, co-expressed with autophagy-related proteins in IBM, contributed to muscle damage by attenuating autophagic clearance of protein aggregates (67). Cacciottolo et al. found the upregulation of CMA components in sIBM muscle fibres, which revealed cellular attempts to activate CMA and remove protein aggregates (68). However, this attempted compensation might not fully work because of the decreased activity of proteolytic enzymes in lysosomes (55). Arimoclomol, an inducer of heat shock response, can upregulate chaperone expression, thereby promoting CMA in stressed cells and curbing the formation of protein aggregates. Treatment with arimoclomol ameliorated IBM-like pathology in myoblasts and mutant VCP mice, and it was safe and well tolerated in a proof-of-concept clinical trial of IBM patients (69). To further evaluate the efficacy of this drug in IBM, a multisite phase II clinical trial has been completed (Clinical Trial Identifier NCT02753530). Moreover, RE could facilitate fusion between autophagosomes and lysosomes in IBM animal models, hence improving impaired macroautophagy (70).

In addition to IBM, autophagy activation could also be detected in PM, DM and IMNM muscle tissues, whereas the autophagic activation, modulation and interaction with the immune system, are different in each type of IIM $(60,71,72)$. In IBM, lysosomal enzymes Cathepsin B and D, are inhibited, while in PM, their activities were actually increased (55). Dysfunctional CMA (73) and mitophagy (a specific autophagic elimination of mitochondria) (74), were reported to occur in IMNM muscles. The decreased autophagy and increased apoptosis of circulating $\mathrm{CD}^{+} \mathrm{T}$ cells have been demonstrated in PM/DM patients, and this phenomenon could be turned around by the treatment of autophagy inducer rapamycin, hence preventing lymphopenia, which suggested that autophagy may play a potential cytoprotective role in PM/DM via inhibition of apoptosis in $\mathrm{CD}^{+} \mathrm{T}$ cells (13). Intravenous immunoglobulin (IVIG) therapy has been demonstrated to induce autophagy in PBMCs and reduce circulation proinflammatory cytokines in IIM by activating AMPK and inhibiting mTOR phosphorylation, thus mediating anti-inflammatory effect (75). 


\section{NETS AND NETOSIS}

Neutrophils are critical immune cells at the frontline of immune defense, responsible for eliminating pathogens by multiple mechanisms, including phagocytosis, production and release of antimicrobial proteins, and formation of neutrophil extracellular traps (NETs) (76). NETs are web-like structures composed of histones, granular proteins and decondensed chromatin, which could be autoantigens and DAMPs to break immune tolerance in predisposed hosts (77-79). NET-derived mitochondrial DNA could induce type I IFN production through the DNA-sensing cGAS-STING pathway in myeloid cells (80). Antimicrobial peptide LL-37 could activate type I IFN as well (81). Also, the components of NETs are detrimental to vessels and muscles (8286). Citrullinated histones exerted toxic effect to decrease the viability of myotubes (87). Accompanied by the formation of NETs, neutrophils die, which is called the NETosis. Essentially, the internal environment homeostasis of IIM patients is disrupted with abnormal cytokine levels (88), which may generate unexpected NETs formation. These NETs irritate more production of proinflammatory cytokines, maintaining a vicious circle of sustained NETosis. For instance, this lytic process could promote the production of IL- 6 and IL- $1 \beta$ in macrophages (89). If excessive NETs cannot be cleared timely and efficiently by DNase I and macrophages, inflammation and autoimmunity will ensue (90).

IIM patients exhibited significant increased NETs, especially in individuals with ILD, which is resulted from decreased activity of DNase I (91). Low-density granulocytes (LDGs), a unique subset of neutrophils with proinflammatory phenotype, are prone to commit NETosis and secrete proinflammatory cytokines (92). LDGs have been reported to display an increased percentage in PBMCs in DM patients, especially those complicated by ILD, along with increased NETs, which may further contribute to the progression of ILD (93). Abnormal regulation of NETs has been reported to be associated with MSAs. An in vitro study showed that anti-MDA5 $\mathrm{Ab}^{+}$serum could directly induce NET formation (94). Interestingly, NET levels exhibited a significant rise in patients with anti-MDA5 or anti-TIF1 antibodies, yet not in patients with anti-Jo-1 positive (87). Contradictorily, Zhang et al. found patients with anti-Jo-1 antibodies exhibited lower DNase I activity than those without anti-Jo-1 antibodies (91). Therefore, studies with larger sample sizes are needed to clarify the association between MSAs and NETs. NETosis may be related to prognosis as well. Anti-MDA5 antibody positive and hyperferritinemia have been identified as the poor prognostic factors of DM. The level of serum cfDNA, which is the product of NETosis, was reported to significantly increase in anti-MDA5 $\mathrm{Ab}^{+}$subset and hyperferritinemic subset, hence it may be a potential indicator of prognosis (94).

A recent report described the presence of calcium crystalinduced NETosis in JDM. The engulfment of calcium crystals by tissue-infiltrating neutrophils, triggered NETosis which is NADPH oxidase- and complement-dependent (95). Also, circulating immune complexes may contribute to the elevated NET levels in JDM (95). JDM patients can develop atherosclerosis during progression into adulthood. Such IIM-associated cardiovascular disease may be related to the oxidation of high-density lipoprotein (HDL) through NETs-derived MPO (96).

\section{PYROPTOSIS}

Pyroptosis is a lytic and proinflammatory form of PCD depending on gasdermin family. Three pathways have been identified, including the caspase-1-mediated canonical pathway stimulated by PAMPs or DAMPs, the noncanonical pathway requiring caspase-4, 5 (for human) or caspase-11 (for murine) triggered by lipopolysaccharide (LPS), and caspase-3-dependent pathway. The best-studied pyroptosis pathway is that mediated by gasdermin D (GSDMD) with downstream of nucleotide-binding and oligomerization domain-like receptor family pyrin-domain containing 3 (NLRP3) inflammasome activation, which can recruit and activate inflammatory caspases. The activated caspase- 1 or caspase- $4 / 5 / 11$, cleaves GSDMD and exposes its N-terminal domain, which binds to phosphoinositides in the cell membrane and forms large pores, thus driving cytoplasmic swelling, cytolysis, and release of cellular contents (97). Also, caspase-1 cleaves IL-1 $\beta$ and IL-18 to produce mature cytokines, but whether these cytokines are actively secreted or released via pyroptotic membrane rupture remained unclear (98). Other released contents, including cleaved GSDMD, chemokines, ATP and HMGB1, recruit immune cells and expand tissue inflammation (99). Caspase-3, recognized as the apoptotic executioner by convention, has been reported to specifically cleave gasdermin E (GSDME), thereby initiating pyroptosis, and whether cells with caspase- 3 activated undergo apoptosis or pyroptosis, depends on the expression level of GSDME (100).

Currently, the three mentioned pathways have all been demonstrated in muscle tissues of IIMs. Liu et al. first reported that the GSDME-dependent pyroptosis got involved in the pathogenesis of perifascicular atrophy (PFA), a pathognomonic histologic feature of DM (101). Soon afterwards, Ma et al. demonstrated the implication of noncanonical pathway in the animal model of experimental autoimmune myositis (EAM) as well, and glyburide and brilliant blue G (BBG) could lower the levels of pyroptotic markers and alleviate symptoms (102). However, these two studies verified pyroptosis by detecting the full length of GSDME or GSDMD, rather than the cleaved forms. Besides, upregulated glycolysis has been reported in the lesioned muscle tissues of $\mathrm{DM} / \mathrm{PM}$, which further promoted myocyte pyroptosis by activating the NLRP3 inflammasome and exposing N-GSDMD. Treated IFN- $\gamma$ stimulated-myotubes with shikonin, a pyruvate kinase isozyme M2 (PKM2) inhibitor, could mitigate NLRP3 inflammasome activation and suppress pyroptosis (103). Intriguingly, the levels of PKM2 and IL- $1 \beta$ were related to MSAs, and were especially high in patients with anti-SRP autoantibody (103).

\section{OTHER FORMS OF PCD: FERROPTOSIS AND NECROPTOSIS}

\section{Ferroptosis}

Ferroptosis is a newly proposed cell death with unique morphological structures and biochemical expressions, caused 
by oxidative damage due to the excessive accumulation of irondependent lipid peroxidation products. It usually shows necrosis-like morphological changes with mitochondrial abnormalities, such as condensed membrane and reduced or absent crista (104). Whether a cell will undergo ferroptosis is linked with many factors, such as its level of polyunsaturated fatty acid (PUFA), iron metabolism, and glutathione (GSH) biosynthesis. The inhibition of cystine-glutamate antiporter (system Xc-) and the inactivation of GSH peroxidase-4 (GPX4) lead to the depletion of cellular GSH, and the impaired clearance of ROS, thus causing collapse of cellular redox homeostasis and accumulation of ROS from lipid peroxidation or Fenton reaction, ultimately resulting in lipid membrane damages and cell death (7). Ferroptotic peroxidation products are powerful inducers of autophagy (e.g., reactive aldehydes) (104), and excessive autophagy promotes ferroptosis in turn, by degrading ironstorage protein ferritin and hence increasing cellular iron concentration (105). This specific autophagic process is called ferritinophagy. Of note, hyperferritinemia is frequently accompanied by IIM-ILD, and is associated with disease severity and prognosis (106). Moreover, mitochondria play a proactive role in cysteine-deprivation-induced ferroptosis by fueling metabolism and lipid ROS production (107). Besides, mitochondrial abnormalities and increased level of ROS, have been reported in IIM, proposed to be vital mediators in IIM pathophysiology (108-110). Taken together, it is logical to hypothesize that ferroptosis is implicated in the development of IIM, so further in-depth studies are necessary to elucidate the exact role of ferroptosis in IIMs.

\section{Necroptosis}

Necroptosis is an inflammatory form of PCD characterized by receptor-interacting protein kinase 3- (RIPK3-) mediated activation of mixed lineage kinase domain-like protein (MLKL) and permeabilization of the plasma membrane (111). Although apoptosis and necroptosis frequently share common triggers, including death receptors and IFN, downstream signaling pathway of these triggers leading to survival, apoptosis or necroptosis depends on the availability of cellular inhibitor of apoptosis (cIAPs), FLIP, or caspase-8 (112). In the absence of caspase-8, the necrosome (i.e., RIPK1/RIPK3 complex) activates necroptotic pathway, thus promoting the recruitment and phosphorylation of MLKL, and then, the activated MLKL translocates to the cell membrane and damages the integrity, leading to the release of cell contents and generating inflammation (113). In addition, necroptosis regulators RIPK3 and MLKL have been reported to play an independent role in inflammation irrespective of cell death - promoting NLRP3 inflammasome activation and IL-1 $\beta$ secretion $(114,115)$. Collectively, these results indicated that necroptosis can enhance inflammation and may be implicated in the pathogenesis and progression of autoimmune diseases. For instance, necroptosis has been reported to contribute to B-cell lymphopenia in systemic lupus erythematosus (116). IFN- $\gamma$ could downregulate necroptosis by inhibiting MLKL and cFLIP, thereby exerting protective effects in autoimmune arthritis (117). GSK2982772 is a highly selective inhibitor of
RIPK1, while a latest randomized, placebo-controlled study found GSK2982772 no meaningful clinical improvement of RA compared with placebo (118). No studies investigate the association between IIM and necroptosis currently.

\section{CROSSTALK BETWEEN PCD PATHWAYS}

The PCD pathways are tightly connected and the cross regulation between them is complex. In most circumstances, apoptosis and autophagy are mutually inhibited. Autophagy can reduce the abundance of pro-apoptotic proteins in the cytosol (e.g., caspase-8), while activated caspases can degrade essential autophagic proteins (e.g., BECN1) (119). On the contrary, there is a mutual promotion between ferroptosis and autophagy, which is discussed above in the 'Ferroptosis' section.

Different cell death pathways can be activated with the same signal. For example, disturbed redox homeostasis and excessive ROS attributed to sustained activation of ER stress pathway, which is clearly of etiological relevance in IIM (120), could activate all the PCD pathways aforementioned. Moreover, biochemical and cellular consequences of one type of cell death can have profound influence on the activity of another type of cell death (121). GSDMD, the executor of pyroptosis, also plays a crucial role in NETosis. During NETosis, serine proteases released from neutrophil granules could cleave GSDMD, and then activated GSDMD in turn permeabilizes granules to enhance proteases release and promotes nuclear expansion. Further, activated GSDMD forms pores in the plasma membrane, promoting NET release (122).

Various cell death modes can coexist, and cells can switch between one death pathway to another. Caspase- 8 is a crucial molecular switch for apoptosis, necroptosis and pyroptosis. It can not only directly cleave caspase-3 to induce extrinsic apoptosis, but also get involved in other cell death pathways. When TGF- $\beta$ activated kinase-1 (TAK1, cell survival kinase) is inhibited, caspase- 8 could cleave GSDMD and induce pyroptosis (123). The loss of caspase- 8 or its enzymatic activity could lead to MLKL-dependent necroptosis. If necroptosis is blocked, enzymatic inactive caspase- 8 could indirectly activate GSDMD and cause pyroptosis by driving ASC (apoptosis-associated specklike protein, adaptor protein of NLRP3 inflammasome) speck formation, which leads to caspase-1 activation (124). Overall, increasing evidence points to caspase- 8 as a central regulator of cell death, and it promotes apoptosis, necroptosis, or pyroptosis depending on its posttranslational state, the cell type, and the stimuli (125). The intricate crosstalk between pyroptosis, apoptosis, and necroptosis has led to the proposal of PANoptosis. It is regulated by the PANoptosome complex, a molecular scaffold for the contemporaneous engagement of key pyroptotic, apoptotic, and necroptotic machinery (125). PANoptosis has been reported in microbial infection, inflammatory diseases, cancer and cytokine storm. For instance, in COVID-19, increased circulating levels of TNF and IFN- $\gamma$ synergistically induce PANoptosis characterized by activation of pyroptotic (GSDME), apoptotic (caspase-8/3/7) and necroptotic (pMLKL) molecules, facilitate further pathogenic cytokine release 
TABLE 1 | Factors inducing abnormal myocyte death in IIMs.

\begin{tabular}{|c|c|c|c|c|}
\hline Factors & Death pathways & Effects & Year & References \\
\hline Perforin, granzyme B & Apoptosis & Exert direct cytotoxicity & 2016 & (30) \\
\hline IFN- $\gamma$, TNF & $\begin{array}{l}\text { Apoptosis, } \\
\text { autophagy }\end{array}$ & Induce surface expression of $\mathrm{MHC}$ & 2011, 2016 & $(30,31,61)$ \\
\hline$A \beta$, IFN- $\gamma$ & Apoptosis & Stimulate $\mathrm{NO}_{2}^{-}$production via induction of iNOS gene expression & 2000, 2001 & $(32,33)$ \\
\hline Mutations in gene GNE & Apoptosis & Increase caspases-3 and -9 expression & 2007 & $(34)$ \\
\hline IFN- $\gamma$, TNF, IL-1 $\beta$ & Apoptosis & Increase Fas, caspases-3 and -8 expression & 2009 & (35) \\
\hline Mutations in gene VCP & $\begin{array}{l}\text { Autophagy, } \\
\text { apoptosis }\end{array}$ & Lead to impaired protein degradation & 2009 & (53) \\
\hline $\begin{array}{l}\text { Missense variants in gene } \\
\text { FYCO1 }\end{array}$ & Autophagy & Lead to impaired microtubule transport of autophagosomes & 2017 & $(54)$ \\
\hline IL-1 $\beta$, IFN- $\gamma$ & Autophagy & $\begin{array}{l}\text { Increase phosphorylation of the mitogen activated protein kinases and induce } \\
\text { accumulation of amyloid }\end{array}$ & 2017 & $(58)$ \\
\hline TRAIL & Autophagy & Induce NF- $\kappa \mathrm{B}$ activation and autophagic cell death & 2011 & $(60)$ \\
\hline MSAs & NETosis & Unclear & $\begin{array}{l}2014,2018 \\
2020\end{array}$ & $(87,91,94)$ \\
\hline $\begin{array}{l}\text { Calcium crystal, immune } \\
\text { complexes }\end{array}$ & NETosis & Induce formation of NETs & 2020 & (95) \\
\hline PKM2 & Pyroptosis & Activate NLRP3 inflammasome & 2021 & $(103)$ \\
\hline
\end{tabular}

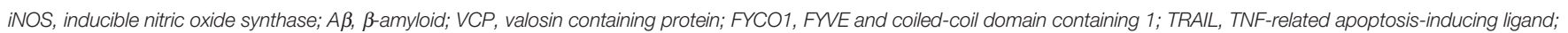
PKM2, pyruvate kinase isozyme M2.

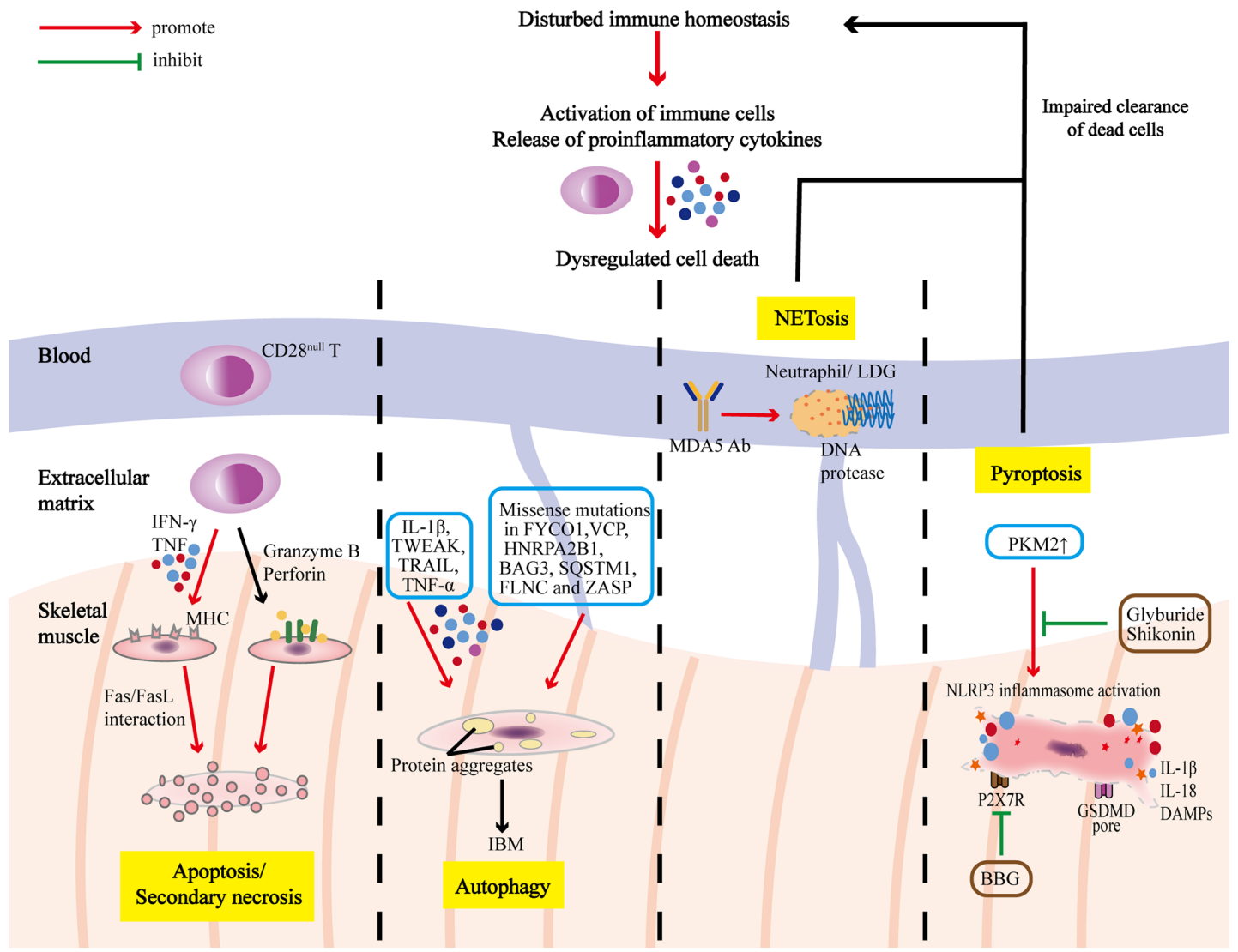

FIGURE 2 | PCD pathways in the pathogenesis and progression of IIMs. The immune homeostasis of IIM patients is disrupted with activation of immune cells and release of proinflammatory cytokines, which could lead to dysregulated cell death. T cells infiltrating in the muscles are dominated by CD28 ${ }^{\text {null }} T$ cells, which are apoptosis-resistant, and could exert polarize perforin and secrete granzyme B to induce myocyte apoptosis, or release IFN- $\gamma$ and TNF to induce surface expression of $\mathrm{MHC}$, rendering the myocytes more sensitive to cytotoxic attacks. Overmuch autophagy and impaired protein degradation result in accumulation of multiprotein aggregates, which causes myocyte degeneration characteristic of IBM. Excessive programmed necrosis (such as NETosis and pyroptosis) contribute to the release of proinflammatory cytokines, and DAMPs, and activation of NLRP3 inflammasome, further amplifying immune responses. 
TABLE 2 | Possible therapeutic targets for IIMs.

\begin{tabular}{llllr}
\hline Targets & Interventions & Death pathway & Year & References \\
\hline A $\beta$ / & Resistance & Apoptosis, & 2017 & $(42,70)$ \\
macroautophagy & exercise & autophagy & 2019 & \\
FAP & Exercise and & Apoptosis & 2020 & $(45)$ \\
& AMPK & & & \\
Calpain & Calpeptin & Apoptosis & 2010, & $(31,46)$ \\
& & & 2011 & \\
Cathepsin B & CA-074Me & Apoptosis & 2013, & $(47,48)$ \\
& & & 2015 & \\
mTOR & Rapamycin & Autophagy & 2017 & $(13)$ \\
Heat Shock & Arimoclomol & Autophagy & 2016 & $(69)$ \\
Factor-1 & & & & \\
AMPK & IVIG & Autophagy & 2018 & $(74)$ \\
NLRP3 & Glyburide & Pyroptosis & 2021 & $(102)$ \\
P2X7 receptor & Brilliant blue G & Pyroptosis & 2021 & $(102)$ \\
PKM2 & Shikonin & Pyroptosis & 2021 & $(103)$ \\
\hline
\end{tabular}

$A \beta$, $\beta$-amyloid; FAP, fibro-adipogenic progenitor; AMPK, AMP-activated protein kinase; mTOR, mammalian target of rapamycin; IVIG, intravenous immunoglobulin; $P 2 X 7$, adenosine triphosphate gated cationic channel; PKM2, pyruvate kinase isozyme M2.

through membrane pores and cell lysis, culminating in a lifethreatening cytokine storm (126). Whether PANoptosis occurs in anti-MDA5-associated ILD, which is prone to be complicated by cytokine storm, remains uninvestigated.

Therefore, due to the intricacies and connections between each PCD pathways, which death pathway is dominant, and whether there is synergy and the simultaneous activation of multiple pathways in IIM need to be considered. Taking an integral view of cell death in IIM may improve our understanding of pathogenesis and aid in the development of therapeutics.

\section{CONCLUSION}

Immune and non-immune factors contribute to abnormal cell death in IIMs (Table 1), and dysregulation of PCD further amplifies inflammatory responses, playing an important part in

\section{REFERENCES}

1. Lundberg IE, de Visser M, Werth VP. Classification of Myositis. Nat Rev Rheumatol (2018) 14(5):269-78. doi: 10.1038/nrrheum.2018.41

2. Zanframundo G, Tripoli A, Cometi L, Marcucci E, Furini F, Cavagna L, et al. One Year in Review 2020: Idiopathic Inflammatory Myopathies. Clin Exp Rheumatol (2020) 39:1-12.

3. McHugh NJ, Tansley SL. Autoantibodies in Myositis. Nat Rev Rheumatol (2018) 14(5):290-302. doi: 10.1038/nrrheum.2018.56

4. Greenberg SA. Dermatomyositis and Type 1 Interferons. Curr Rheumatol Rep (2010) 12(3):198-203. doi: 10.1007/s11926-010-0101-6

5. Vanden Berghe T, Linkermann A, Jouan-Lanhouet S, Walczak H, Vandenabeele P. Regulated Necrosis: The Expanding Network of nonApoptotic Cell Death Pathways. Nat Rev Mol Cell Biol (2014) 15(2):135-47. doi: $10.1038 / \mathrm{nrm} 3737$

6. Kroemer G, Galluzzi L, Vandenabeele P, Abrams J, Alnemri ES, Baehrecke $\mathrm{EH}$, et al. Classification of Cell Death: Recommendations of the Nomenclature Committee on Cell Death 2009. Cell Death differentiation (2009) 16(1):3-11. doi: 10.1038/cdd.2008.150

7. Kim EH, Wong SW, Martinez J. Programmed Necrosis and Disease:We Interrupt Your Regular Programming to Bring You Necroinflammation. the pathogenesis and progression of IIM (Figure 2), although it has not been unveiled clearly. Further in-depth studies on these PCD pathways will extend our knowledge on the pathogenic mechanism of IIMs, and targeting different steps to inhibit PCD processes and promoting the clearance of death materials may be promising therapeutic strategies for IIMs (Table 2). In addition, the particularity of autoantibodies is noteworthy, as patients with diverse autoantibodies exhibit different clinical manifestations, prognosis, organ involvements, and treatment responses, suggesting that potential immunopathogenic mechanisms may be different. Besides, targeted antigens by MSAs are intracellular components, so we speculate that their exposure to immune system and followed generation of MSAs are attributed to the dysregulation of PCD. Therefore, it's reasonable to put emphasis on the association of distinct MSAs with PCD pathways in further studies. Also, PCD pathways are intimately linked and interdependent, making it necessary to take a comprehensive approach to investigate PCD pathways.

\section{AUTHOR CONTRIBUTIONS}

JS collected materials and wrote the paper. QW, MT, SZ, and CW provided the idea and reviewed the manuscript. DX, JZ, XT, ML, and XZ helped with the final revision of the paper. All authors contributed to the article and approved the submitted version.

\section{FUNDING}

This work was supported by the Beijing Municipal Science and Technology Commission (Z201100005520025), CAMS Innovation Fund for Medical Sciences (CIFMS) (2019-I2M-2008), and the National Natural Science Foundation of China $(81471615,81601430)$.
Cell Death differentiation (2019) 26(1):25-40. doi: 10.1038/s41418-0180179-3

8. Van Opdenbosch N, Lamkanfi M. Caspases in Cell Death, Inflammation, and Disease. Immunity (2019) 50(6):1352-64. doi: 10.1016/ j.immuni.2019.05.020

9. Riedl SJ, Salvesen GS. The Apoptosome: Signalling Platform of Cell Death. Nat Rev Mol Cell Biol (2007) 8(5):405-13. doi: 10.1038/nrm2153

10. Czabotar PE, Lessene G, Strasser A, Adams JM. Control of Apoptosis by the BCL-2 Protein Family: Implications for Physiology and Therapy. Nat Rev Mol Cell Biol (2014) 15(1):49-63. doi: 10.1038/nrm3722

11. Nagata S. Apoptosis and Clearance of Apoptotic Cells. Annu Rev Immunol (2018) 36:489-517. doi: 10.1146/annurev-immunol-042617-053010

12. Zhang L, Xia Q, Li W, Peng Q, Yang H, Lu X, et al. The RIG-I Pathway is Involved in Peripheral T Cell Lymphopenia in Patients With Dermatomyositis. Arthritis Res Ther (2019) 21(1):131. doi: 10.1186/s13075-019-1905-Z

13. Shu X, Chen F, Peng Q, Lu X, Tian X, Wang Y, et al. Potential Role of Autophagy in T-cell Survival in Polymyositis and Dermatomyositis. Mol Med Rep (2017) 16(2):1180-8. doi: 10.3892/mmr.2017.6693

14. Strioga M, Pasukoniene V, Characiejus D. CD8+ CD28- and CD8+ CD57+ $\mathrm{T}$ Cells and Their Role in Health and Disease. Immunology (2011) 134 (1):17-32. doi: 10.1111/j.1365-2567.2011.03470.x 
15. Espinosa-Ortega F, Gómez-Martin D, Santana-De Anda K, Romo-Tena J, Villaseñor-Ovies P, Alcocer-Varela J. Quantitative T Cell Subsets Profile in Peripheral Blood From Patients With Idiopathic Inflammatory Myopathies: Tilting the Balance Towards Proinflammatory and Pro-Apoptotic Subsets. Clin Exp Immunol (2015) 179(3):520-8. doi: 10.1111/cei.12475

16. Fasth AE, Dastmalchi M, Rahbar A, Salomonsson S, Pandya JM, Lindroos E, et al. T Cell Infiltrates in the Muscles of Patients With Dermatomyositis and Polymyositis are Dominated by CD28null T Cells. J Immunol (Baltimore Md 1950) (2009) 183(7):4792-9. doi: 10.4049/jimmunol.0803688

17. Pandya JM, Loell I, Hossain MS, Zong M, Alexanderson H, Raghavan S, et al. Effects of Conventional Immunosuppressive Treatment on CD244+ (CD28null) and FOXP3+ T Cells in the Inflamed Muscle of Patients With Polymyositis and Dermatomyositis. Arthritis Res Ther (2016) 18:80. doi: 10.1186/s13075-016-0974-5

18. Pandya JM, Fasth AE, Zong M, Arnardottir S, Dani L, Lindroos E, et al. Expanded T Cell Receptor V $\beta$-Restricted T Cells From Patients With Sporadic Inclusion Body Myositis are Proinflammatory and Cytotoxic CD28null T Cells. Arthritis Rheumatism (2010) 62(11):3457-66. doi: 10.1002/art.27665

19. Posnett DN, Edinger JW, Manavalan JS, Irwin C, Marodon G. Differentiation of Human CD8 T Cells: Implications for In Vivo Persistence of CD8+ CD28- Cytotoxic Effector Clones. Int Immunol (1999) 11(2):229-41. doi: 10.1093/intimm/11.2.229

20. Vattemi G, Tonin P, Filosto M, Spagnolo M, Rizzuto N, Tomelleri G. T-Cell Anti-Apoptotic Mechanisms in Inflammatory Myopathies. J Neuroimmunology (2000) 111(1-2):146-51. doi: 10.1016/S0165-5728(00) 00381-7

21. Liphaus BL, Sallum AEM, Aikawa NE, Kiss MHB, Carrasco S, Palmeira P, et al. Increased Soluble Cytoplasmic Bcl-2 Protein Serum Levels and Expression and Decreased Fas Expression in Lymphocytes and Monocytes in Juvenile Dermatomyositis. J Rheumatol (2018) 45(11):1577-80. doi: 10.3899/jrheum.171248

22. Wood KL, Twigg HL3rd, Doseff AI. Dysregulation of CD8+ Lymphocyte Apoptosis, Chronic Disease, and Immune Regulation. Front Biosci (Landmark edition) (2009) 14:3771-81. doi: 10.2741/3487

23. Strauss G, Knape I, Melzner I, Debatin KM. Constitutive Caspase Activation and Impaired Death-Inducing Signaling Complex Formation in CD95-Resistant, Long-Term Activated, Antigen-Specific T Cells. Jimmunol (Baltimore Md 1950) (2003) 171(3):1172-82. doi: 10.4049/jimmunol.171.3.1172

24. Gunturi A, Berg RE, Forman J. Preferential Survival of CD8 T and NK Cells Expressing High Levels of CD94. J Immunol (Baltimore Md 1950) (2003) 170 (4):1737-45. doi: 10.4049/jimmunol.170.4.1737

25. Plunkett FJ, Franzese O, Finney HM, Fletcher JM, Belaramani LL, Salmon $\mathrm{M}$, et al. The Loss of Telomerase Activity in Highly Differentiated CD8 +CD28-CD27- T Cells is Associated With Decreased Akt (Ser473) Phosphorylation. J Immunol (Baltimore Md 1950) (2007) 178(12):7710-9. doi: 10.4049/jimmunol.178.12.7710

26. Hodge G, Jersmann H, Tran HB, Holmes M, Reynolds PN, Hodge S. Lymphocyte Senescence in COPD is Associated With Loss of Glucocorticoid Receptor Expression by Pro-Inflammatory/Cytotoxic Lymphocytes. Respir Res (2015) 16(1):2. doi: 10.1186/s12931-015-0287-2

27. Barbarino JM, Staatz CE, Venkataramanan R, Klein TE, Altman RB. PharmGKB Summary: Cyclosporine and Tacrolimus Pathways. Pharmacogenet Genomics (2013) 23(10):563-85. doi: 10.1097/ FPC.0b013e328364db84

28. Takada K, Katada Y, Ito S, Hayashi T, Kishi J, Itoh K, et al. Impact of Adding Tacrolimus to Initial Treatment of Interstitial Pneumonitis in Polymyositis/ Dermatomyositis: A Single-Arm Clinical Trial. Rheumatol (Oxford England) (2020) 59(5):1084-93. doi: 10.1093/rheumatology/kez394

29. Tjärnlund A, Tang Q, Wick C, Dastmalchi M, Mann H, Tomasová Studýnková J, et al. Abatacept in the Treatment of Adult Dermatomyositis and Polymyositis: A Randomised, Phase IIb Treatment Delayed-Start Trial. Ann rheumatic Dis (2018) 77(1):55-62. doi: 10.1136/annrheumdis-2017211751

30. Pandya JM, Venalis P, Al-Khalili L, Shahadat Hossain M, Stache V, Lundberg IE, et al. CD4+ and CD8+ CD28(null) T Cells Are Cytotoxic to Autologous Muscle Cells in Patients With Polymyositis. Arthritis Rheumatol (Hoboken NJ) (2016) 68(8):2016-26. doi: 10.1002/art.39650
31. Nozaki K, Das A, Ray SK, Banik NL. Calpeptin Attenuated Apoptosis and Intracellular Inflammatory Changes in Muscle Cells. J Neurosci Res (2011) 89(4):536-43. doi: 10.1002/jnr.22585

32. Baron P, Galimberti D, Meda L, Prat E, Scarpini E, Conti G, et al. Synergistic Effect of Beta-Amyloid Protein and Interferon Gamma on Nitric Oxide Production by C2C12 Muscle Cells. Brain J Neurol (2000) 123( Pt 2):374-9. doi: 10.1093/brain/123.2.374

33. Querfurth HW, Suhara T, Rosen KM, McPhie DL, Fujio Y, Tejada G, et al. Beta-Amyloid Peptide Expression is Sufficient for Myotube Death: Implications for Human Inclusion Body Myopathy. Mol Cell Neurosci (2001) 17(5):793-810. doi: 10.1006/mcne.2001.0972

34. Amsili S, Shlomai Z, Levitzki R, Krause S, Lochmuller H, Ben-Bassat H, et al. Characterization of Hereditary Inclusion Body Myopathy Myoblasts: Possible Primary Impairment of Apoptotic Events. Cell Death differentiation (2007) 14(11):1916-24. doi: 10.1038/sj.cdd.4402208

35. Kondo M, Murakawa Y, Harashima N, Kobayashi S, Yamaguchi S, Harada M. Roles of Proinflammatory Cytokines and the Fas/Fas Ligand Interaction in the Pathogenesis of Inflammatory Myopathies. Immunology (2009) 128(1 Suppl):e589-99. doi: 10.1111/j.1365-2567.2008.03039.x

36. Behrens L, Bender A, Johnson MA, Hohlfeld R. Cytotoxic Mechanisms in Inflammatory Myopathies. Co-Expression of Fas and Protective Bcl-2 in Muscle Fibres and Inflammatory Cells. Brain J Neurol (1997) 120( Pt 6):92938. doi: 10.1093/brain/120.6.929

37. Danielsson O, Häggqvist B, Gröntoft L, Öllinger K, Ernerudh J. Apoptosis in Idiopathic Inflammatory Myopathies With Partial Invasion; a Role for CD8+ Cytotoxic T Cells? PloS One (2020) 15(9):e0239176. doi: 10.1371/ journal.pone.0239176

38. De Bleecker JL, Meire VI, Van Walleghem IE, Groessens IM, Schröder JM. Immunolocalization of FAS and FAS Ligand in Inflammatory Myopathies. Acta Neuropathol (2001) 101(6):572-8. doi: 10.1007/s004010000324

39. Danielsson O, Nilsson C, Lindvall B, Ernerudh J. Expression of Apoptosis Related Proteins in Normal and Diseased Muscle: A Possible Role for Bcl-2 in Protection of Striated Muscle. Neuromuscular Disord NMD (2009) 19 (6):412-7. doi: 10.1016/j.nmd.2009.03.008

40. Nagaraju K, Casciola-Rosen L, Rosen A, Thompson C, Loeffler L, Parker T, et al. The Inhibition of Apoptosis in Myositis and in Normal Muscle Cells. J Immunol (Baltimore Md 1950) (2000) 164(10):5459-65. doi: 10.4049/ jimmunol.164.10.5459

41. Li M, Dalakas MC. Expression of Human IAP-Like Protein in Skeletal Muscle: A Possible Explanation for the Rare Incidence of Muscle Fiber Apoptosis in T-Cell Mediated Inflammatory Myopathies. J Neuroimmunology (2000) 106(1-2):1-5. doi: 10.1016/S0165-5728(99)00162-9

42. Koo JH, Kang EB, Cho JY. Resistance Exercise Improves Mitochondrial Quality Control in a Rat Model of Sporadic Inclusion Body Myositis. Gerontology (2019) 65(3):240-52. doi: 10.1159/000494723

43. Dalakas MC, Rakocevic G, Schmidt J, Salajegheh M, McElroy B, Harris-Love $\mathrm{MO}$, et al. Effect of Alemtuzumab (CAMPATH 1-H) in Patients With Inclusion-Body Myositis. Brain J Neurol (2009) 132(Pt 6):1536-44. doi: 10.1093/brain/awp104

44. Nückel H, Frey UH, Röth A, Dührsen U, Siffert W. Alemtuzumab Induces Enhanced Apoptosis In Vitro in B-Cells From Patients With Chronic Lymphocytic Leukemia by Antibody-Dependent Cellular Cytotoxicity. Eur J Pharmacol (2005) 514(2-3):217-24. doi: 10.1016/j.ejphar.2005.03.024

45. Saito Y, Chikenji TS, Matsumura T, Nakano M, Fujimiya M. Exercise Enhances Skeletal Muscle Regeneration by Promoting Senescence in Fibro-Adipogenic Progenitors. Nat Commun (2020) 11(1):889. doi: 10.1038/s41467-020-14734-x

46. Nozaki K, Das A, Ray SK, Banik NL. Calpain Inhibition Attenuates Intracellular Changes in Muscle Cells in Response to Extracellular Inflammatory Stimulation. Exp Neurol (2010) 225(2):430-5. doi: 10.1016/ j.expneurol.2010.07.021

47. Feng Y, Ni L, Wang Q. Administration of Cathepsin B Inhibitor CA-074Me Reduces Inflammation and Apoptosis in Polymyositis. J Dermatol Sci (2013) 72(2):158-67. doi: 10.1016/j.jdermsci.2013.06.014

48. Zhang L, Fu XH, Yu Y, Shui RH, Li C, Zeng HY, et al. Treatment With CA$074 \mathrm{Me}$, a Cathepsin B Inhibitor, Reduces Lung Interstitial Inflammation and Fibrosis in a Rat Model of Polymyositis. Lab Invest J Tech Methods Pathol (2015) 95(1):65-77. doi: 10.1038/labinvest.2014.135 
49. Choi AM, Ryter SW, Levine B. Autophagy in Human Health and Disease. New Engl J Med (2013) 368(7):651-62. doi: 10.1056/NEJMra1205406

50. Ge Y, Huang M, Yao YM. Autophagy and Proinflammatory Cytokines: Interactions and Clinical Implications. Cytokine Growth factor Rev (2018) 43:38-46. doi: 10.1016/j.cytogfr.2018.07.001

51. Galluzzi L, Vitale I, Aaronson SA, Abrams JM, Adam D, Agostinis P, et al. Molecular Mechanisms of Cell Death: Recommendations of the Nomenclature Committee on Cell Death 2018. Cell Death differentiation (2018) 25(3):486-541. doi: 10.1038/s41418-017-0012-4

52. Britson KA, Yang SY, Lloyd TE. New Developments in the Genetics of Inclusion Body Myositis. Curr Rheumatol Rep (2018) 20(5):26. doi: 10.1007/ s11926-018-0738-0

53. Vesa J, Su H, Watts GD, Krause S, Walter MC, Martin B, et al. Valosin Containing Protein Associated Inclusion Body Myopathy: Abnormal Vacuolization, Autophagy and Cell Fusion in Myoblasts. Neuromuscular Disord NMD (2009) 19(11):766-72. doi: 10.1016/j.nmd.2009.08.003

54. Güttsches AK, Brady S, Krause K, Maerkens A, Uszkoreit J, Eisenacher M, et al. Proteomics of Rimmed Vacuoles Define New Risk Allele in Inclusion Body Myositis. Ann Neurol (2017) 81(2):227-39. doi: 10.1002/ana.24847

55. Nogalska A, D'Agostino C, Terracciano C, Engel WK, Askanas V. Impaired Autophagy in Sporadic Inclusion-Body Myositis and in Endoplasmic Reticulum Stress-Provoked Cultured Human Muscle Fibers. Am J Pathol (2010) 177(3):1377-87. doi: 10.2353/ajpath.2010.100050

56. de Camargo LV, de Carvalho MS, Shinjo SK, de Oliveira ASB, Zanoteli E. Clinical, Histological, and Immunohistochemical Findings in Inclusion Body Myositis. BioMed Res Int (2018) 2018:5069042. doi: 10.1155/2018/ 5069042

57. Hiniker A, Daniels BH, Lee HS, Margeta M. Comparative Utility of LC3, P62 and TDP-43 Immunohistochemistry in Differentiation of Inclusion Body Myositis From Polymyositis and Related Inflammatory Myopathies. Acta Neuropathol Commun (2013) 1:29. doi: 10.1186/2051-5960-1-29

58. Schmidt K, Wienken M, Keller CW, Balcarek P, Münz C, Schmidt J. IL-1 $\beta$ Induced Accumulation of Amyloid: Macroautophagy in Skeletal Muscle Depends on ERK. Mediators Inflammation (2017) 2017:5470831. doi: $10.1155 / 2017 / 5470831$

59. Bhatnagar S, Mittal A, Gupta SK, Kumar A. TWEAK Causes Myotube Atrophy Through Coordinated Activation of Ubiquitin-Proteasome System, Autophagy, and Caspases. J Cell Physiol (2012) 227(3):1042-51. doi: 10.1002/ jcp. 22821

60. Alger HM, Raben N, Pistilli E, Francia DL, Rawat R, Getnet D, et al. The Role of TRAIL in Mediating Autophagy in Myositis Skeletal Muscle: A Potential Nonimmune Mechanism of Muscle Damage. Arthritis Rheumatism (2011) 63(11):3448-57. doi: 10.1002/art.30530

61. Keller CW, Fokken C, Turville SG, Lünemann A, Schmidt J, Münz C, et al. TNF-Alpha Induces Macroautophagy and Regulates MHC Class II Expression in Human Skeletal Muscle Cells. J Biol Chem (2011) 286 (5):3970-80. doi: 10.1074/jbc.M110.159392

62. Loi M, Müller A, Steinbach K, Niven J, Barreira da Silva R, Paul P, et al. Macroautophagy Proteins Control MHC Class I Levels on Dendritic Cells and Shape Anti-Viral CD8(+) T Cell Responses. Cell Rep (2016) 15(5):107687. doi: 10.1016/j.celrep.2016.04.002

63. Lünemann JD, Schmidt J, Schmid D, Barthel K, Wrede A, Dalakas MC, et al. Beta-Amyloid is a Substrate of Autophagy in Sporadic Inclusion Body Myositis. Ann Neurol (2007) 61(5):476-83. doi: 10.1002/ana.21115

64. Girolamo F, Lia A, Amati A, Strippoli M, Coppola C, Virgintino D, et al. Overexpression of Autophagic Proteins in the Skeletal Muscle of Sporadic Inclusion Body Myositis. Neuropathol Appl Neurobiol (2013) 39(7):736-49. doi: $10.1111 /$ nan. 12040

65. Nakano S, Oki M, Kusaka H. The Role of P62/SQSTM1 in Sporadic Inclusion Body Myositis. Neuromuscular Disord NMD (2017) 27(4):363-9. doi: 10.1016/j.nmd.2016.12.009

66. Shtifman A, Ward CW, Laver DR, Bannister ML, Lopez JR, Kitazawa M, et al. Amyloid- $\beta$ Protein Impairs Ca2+ Release and Contractility in Skeletal Muscle. Neurobiol Aging (2010) 31(12):2080-90. doi: 10.1016/ j.neurobiolaging.2008.11.003

67. Yamashita S, Matsuo Y, Tawara N, Hara K, Yamamoto M, Nishikami T, et al. CYLD Dysregulation in Pathogenesis of Sporadic Inclusion Body Myositis. Sci Rep (2019) 9(1):11606. doi: 10.1038/s41598-019-48115-2
68. Cacciottolo M, Nogalska A, D'Agostino C, Engel WK, Askanas V. Chaperone-Mediated Autophagy Components are Upregulated in Sporadic Inclusion-Body Myositis Muscle Fibres. Neuropathol Appl Neurobiol (2013) 39(7):750-61. doi: 10.1111/nan.12038

69. Ahmed M, Machado PM, Miller A, Spicer C, Herbelin L, He J, et al. Targeting Protein Homeostasis in Sporadic Inclusion Body Myositis. Sci Trans Med (2016) 8(331):331ra41. doi: 10.1126/scitranslmed.aad4583

70. Jeong JH, Yang DS, Koo JH, Hwang DJ, Cho JY, Kang EB. Effect of Resistance Exercise on Muscle Metabolism and Autophagy in sIBM. Med Sci sports Exercise (2017) 49(8):1562-71. doi: 10.1249/MSS.0000000000001286

71. Cappelletti C, Galbardi B, Kapetis D, Vattemi G, Guglielmi V, Tonin P, et al. Autophagy, Inflammation and Innate Immunity in Inflammatory Myopathies. PloS One (2014) 9(11):e111490. doi: 10.1371/journal.pone.0111490

72. Girolamo F, Lia A, Annese T, Giannini M, Amati A, D'Abbicco D, et al. Autophagy Markers LC3 and P62 Accumulate in Immune-Mediated Necrotizing Myopathy. Muscle Nerve (2019) 60(3):315-27. doi: 10.1002/ mus. 26608

73. Fischer N, Preuße C, Radke J, Pehl D, Allenbach Y, Schneider U, et al. Sequestosome-1 (P62) Expression Reveals Chaperone-Assisted Selective Autophagy in Immune-Mediated Necrotizing Myopathies. Brain Pathol (Zurich Switzerland) (2020) 30(2):261-71. doi: 10.1111/bpa.12772

74. Matsubara S, Bokuda K, Asano Y, Morishima R, Sugaya K, Miyamoto K, et al. Mitophagy in Three Cases of Immune-Mediated Necrotizing Myopathy Associated With Anti-3-Hydroxy-3-Methylglutaryl-Coenzyme A Reductase Autoantibodies: Ultrastructural and Immunohistochemical Studies. Neuromuscular Disord NMD (2018) 28(3):283-8. doi: 10.1016/ j.nmd.2018.01.004

75. Das M, Karnam A, Stephen-Victor E, Gilardin L, Bhatt B, Kumar Sharma V, et al. Intravenous Immunoglobulin Mediates Anti-Inflammatory Effects in Peripheral Blood Mononuclear Cells by Inducing Autophagy. Cell Death Dis (2020) 11(1):50. doi: 10.1038/s41419-020-2249-y

76. Kolaczkowska E, Kubes P. Neutrophil Recruitment and Function in Health and Inflammation. Nat Rev Immunol (2013) 13(3):159-75. doi: 10.1038/ nri3399

77. Knight JS, Carmona-Rivera C, Kaplan MJ. Proteins Derived From Neutrophil Extracellular Traps may Serve as Self-Antigens and Mediate Organ Damage in Autoimmune Diseases. Front Immunol (2012) 3:380. doi: 10.3389/fimmu.2012.00380

78. Carmona-Rivera C, Carlucci PM, Moore E, Lingampalli N, Uchtenhagen H, James E, et al. Synovial Fibroblast-Neutrophil Interactions Promote Pathogenic Adaptive Immunity in Rheumatoid Arthritis. Sci Immunol (2017) 2(10). doi: 10.1126/sciimmunol.aag3358

79. Khandpur R, Carmona-Rivera C, Vivekanandan-Giri A, Gizinski A, Yalavarthi S, Knight JS, et al. NETs are a Source of Citrullinated Autoantigens and Stimulate Inflammatory Responses in Rheumatoid Arthritis. Sci Trans Med (2013) 5(178):178ra40. doi: 10.1126/scitranslmed. 3005580

80. Lood C, Blanco LP, Purmalek MM, Carmona-Rivera C, De Ravin SS, Smith CK, et al. Neutrophil Extracellular Traps Enriched in Oxidized Mitochondrial DNA are Interferogenic and Contribute to Lupus-Like Disease. Nat Med (2016) 22(2):146-53. doi: 10.1038/nm.4027

81. Lu X, Tang Q, Lindh M, Dastmalchi M, Alexanderson H, Popovic Silwerfeldt K, et al. The Host Defense Peptide LL-37 a Possible Inducer of the Type I Interferon System in Patients With Polymyositis and Dermatomyositis. J Autoimmun (2017) 78:46-56. doi: 10.1016/j.jaut.2016.12.003

82. Carmona-Rivera C, Zhao W, Yalavarthi S, Kaplan MJ. Neutrophil Extracellular Traps Induce Endothelial Dysfunction in Systemic Lupus Erythematosus Through the Activation of Matrix Metalloproteinase-2. Ann rheumatic Dis (2015) 74(7):1417-24. doi: 10.1136/annrheumdis2013-204837

83. Saffarzadeh M, Juenemann C, Queisser MA, Lochnit G, Barreto G, Galuska SP, et al. Neutrophil Extracellular Traps Directly Induce Epithelial and Endothelial Cell Death: A Predominant Role of Histones. PloS One (2012) 7 (2):e32366. doi: 10.1371/journal.pone.0032366

84. Caudrillier A, Kessenbrock K, Gilliss BM, Nguyen JX, Marques MB, Monestier $M$, et al. Platelets Induce Neutrophil Extracellular Traps in Transfusion-Related Acute Lung Injury. J Clin Invest (2012) 122(7):266171. doi: $10.1172 / J C I 61303$ 
85. Silvestre-Roig C, Braster Q, Wichapong K, Lee EY, Teulon JM, Berrebeh N, et al. Externalized Histone H4 Orchestrates Chronic Inflammation by Inducing Lytic Cell Death. Nature (2019) 569(7755):236-40. doi: 10.1038/ s41586-019-1167-6

86. Arecco N, Clarke CJ, Jones FK, Simpson DM, Mason D, Beynon RJ, et al. Elastase Levels and Activity are Increased in Dystrophic Muscle and Impair Myoblast Cell Survival, Proliferation and Differentiation. Sci Rep (2016) 6:24708. doi: 10.1038/srep24708

87. Seto N, Torres-Ruiz JJ, Carmona-Rivera C, Pinal-Fernandez I, Pak K, Purmalek MM, et al. Neutrophil Dysregulation is Pathogenic in Idiopathic Inflammatory Myopathies. JCI Insight (2020) 5(3). doi: 10.1172/jci.insight. 134189

88. Dalakas MC. Pathogenesis and Therapies of Immune-Mediated Myopathies. Autoimmun Rev (2012) 11(3):203-6. doi: 10.1016/j.autrev.2011.05.013

89. Warnatsch A, Ioannou M, Wang Q, Papayannopoulos V. Inflammation. Neutrophil Extracellular Traps License Macrophages for Cytokine Production in Atherosclerosis. Sci (New York NY) (2015) 349(6245):31620. doi: $10.1126 /$ science.aaa8064

90. Villanueva E, Yalavarthi S, Berthier CC, Hodgin JB, Khandpur R, Lin AM, et al. Netting Neutrophils Induce Endothelial Damage, Infiltrate Tissues, and Expose Immunostimulatory Molecules in Systemic Lupus Erythematosus. J Immunol (Baltimore Md 1950) (2011) 187(1):538-52. doi: 10.4049/ jimmunol.1100450

91. Zhang S, Shu X, Tian X, Chen F, Lu X, Wang G. Enhanced Formation and Impaired Degradation of Neutrophil Extracellular Traps in Dermatomyositis and Polymyositis: A Potential Contributor to Interstitial Lung Disease Complications. Clin Exp Immunol (2014) 177(1):134-41. doi: 10.1111/cei.12319

92. Carmona-Rivera C, Kaplan MJ. Low-Density Granulocytes: A Distinct Class of Neutrophils in Systemic Autoimmunity. Semin Immunopathol (2013) 35 (4):455-63. doi: 10.1007/s00281-013-0375-7

93. Zhang S, Shen H, Shu X, Peng Q, Wang G. Abnormally Increased LowDensity Granulocytes in Peripheral Blood Mononuclear Cells are Associated With Interstitial Lung Disease in Dermatomyositis. Modern Rheumatol (2017) 27(1):122-9. doi: 10.1080/14397595.2016.1179861

94. Peng Y, Zhang S, Zhao Y, Liu Y, Yan B. Neutrophil Extracellular Traps may Contribute to Interstitial Lung Disease Associated With Anti-MDA5 Autoantibody Positive Dermatomyositis. Clin Rheumatol (2018) 37 (1):107-15. doi: 10.1007/s10067-017-3799-y

95. Duvvuri B, Pachman LM, Morgan G, Khojah AM, Klein-Gitelman M, Curran ML, et al. Neutrophil Extracellular Traps in Tissue and Periphery in Juvenile Dermatomyositis. Arthritis Rheumatol (Hoboken NJ) (2020) 72 (2):348-58. doi: 10.1002/art.41078

96. Smith CK, Vivekanandan-Giri A, Tang C, Knight JS, Mathew A, Padilla RL, et al. Neutrophil Extracellular Trap-Derived Enzymes Oxidize High-Density Lipoprotein: An Additional Proatherogenic Mechanism in Systemic Lupus Erythematosus. Arthritis Rheumatol (Hoboken NJ) (2014) 66(9):2532-44. doi: $10.1002 /$ art. 38703

97. Bergsbaken T, Fink SL, Cookson BT. Pyroptosis: Host Cell Death and Inflammation. Nat Rev Microbiol (2009) 7(2):99-109. doi: 10.1038/ nrmicro2070

98. Kovacs SB, Miao EA. Gasdermins: Effectors of Pyroptosis. Trends Cell Biol (2017) 27(9):673-84. doi: 10.1016/j.tcb.2017.05.005

99. Liu X, Xia S, Zhang Z, Wu H, Lieberman J. Channelling Inflammation: Gasdermins in Physiology and Disease. Nat Rev Drug Discov (2021) 20:1-22. doi: 10.1038/s41573-021-00154-z

100. Jiang M, Qi L, Li L, Li Y. The Caspase-3/GSDME Signal Pathway as a Switch Between Apoptosis and Pyroptosis in Cancer. Cell Death Discovery (2020) 6:112. doi: 10.1038/s41420-020-00349-0

101. Liu M, Li L, Dai T, Hou Y, Li W, Zhao Y, et al. Gasdermine E-Dependent Mitochondrial Pyroptotic Pathway in Dermatomyositis: A Possible Mechanism of Perifascicular Atrophy. J Neuropathol Exp Neurol (2020) 79 (5):551-61. doi: 10.1093/jnen/nlaa023

102. Ma M, Chai K, Deng R. Study of the Correlation Between the Noncanonical Pathway of Pyroptosis and Idiopathic Inflammatory Myopathy. Int Immunopharmacol (2021) 98:107810. doi: 10.1016/j.intimp.2021.107810

103. Liu D, Xiao Y, Zhou B, Gao S, Li L, Zhao L, et al. PKM2-Dependent Glycolysis Promotes Skeletal Muscle Cell Pyroptosis by Activating the
NLRP3 Inflammasome in Dermatomyositis/Polymyositis. Rheumatol (Oxford England) (2021) 60(5):2177-89. doi: 10.1093/rheumatology/keaa473

104. Tang D, Chen X, Kang R, Kroemer G. Ferroptosis: Molecular Mechanisms and Health Implications. Cell Res (2021) 31(2):107-25. doi: 10.1038/s41422020-00441-1

105. Gao M, Monian P, Pan Q, Zhang W, Xiang J, Jiang X. Ferroptosis is an Autophagic Cell Death Process. Cell Res (2016) 26(9):1021-32. doi: 10.1038/ cr.2016.95

106. Gono T, Kawaguchi Y, Hara M, Masuda I, Katsumata Y, Shinozaki M, et al. Increased Ferritin Predicts Development and Severity of Acute Interstitial Lung Disease as a Complication of Dermatomyositis. Rheumatol (Oxford England) (2010) 49(7):1354-60. doi: 10.1093/rheumatology/keq073

107. Gao M, Yi J, Zhu J, Minikes AM, Monian P, Thompson CB, et al. Role of Mitochondria in Ferroptosis. Mol Cell (2019) 73(2):354-63.e3. doi: 10.1016/ j.molcel.2018.10.042

108. Rygiel KA, Miller J, Grady JP, Rocha MC, Taylor RW, Turnbull DM. Mitochondrial and Inflammatory Changes in Sporadic Inclusion Body Myositis. Neuropathol Appl Neurobiol (2015) 41(3):288-303. doi: 10.1111/ nan.12149

109. Boehler JF, Horn A, Novak JS, Li N, Ghimbovschi S, Lundberg IE, et al. Mitochondrial Dysfunction and Role of Harakiri in the Pathogenesis of Myositis. J Pathol (2019) 249(2):215-26. doi: 10.1002/path.5309

110. Meyer A, Laverny G, Allenbach Y, Grelet E, Ueberschlag V, Echaniz-Laguna A, et al. IFN- $\beta$-Induced Reactive Oxygen Species and Mitochondrial Damage Contribute to Muscle Impairment and Inflammation Maintenance in Dermatomyositis. Acta Neuropathol (2017) 134(4):655-66. doi: 10.1007/ s00401-017-1731-9

111. Dhuriya YK, Sharma D. Necroptosis: A Regulated Inflammatory Mode of Cell Death. J Neuroinflamm (2018) 15(1):199. doi: 10.1186/s12974-0181235-0

112. Pasparakis M, Vandenabeele P. Necroptosis and its Role in Inflammation. Nature (2015) 517(7534):311-20. doi: 10.1038/nature14191

113. Weinlich R, Oberst A, Beere HM, Green DR. Necroptosis in Development, Inflammation and Disease. Nat Rev Mol Cell Biol (2017) 18(2):127-36. doi: 10.1038/nrm.2016.149

114. Lawlor KE, Khan N, Mildenhall A, Gerlic M, Croker BA, D'Cruz AA, et al. RIPK3 Promotes Cell Death and NLRP3 Inflammasome Activation in the Absence of MLKL. Nat Commun (2015) 6:6282. doi: 10.1038/ncomms7282

115. Conos SA, Chen KW, De Nardo D, Hara H, Whitehead L, Núñez G, et al. Active MLKL Triggers the NLRP3 Inflammasome in a Cell-Intrinsic Manner. Proc Natl Acad Sci United States America (2017) 114(6):E961-e9. doi: 10.1073/pnas.1613305114

116. Fan H, Liu F, Dong G, Ren D, Xu Y, Dou J, et al. Activation-Induced Necroptosis Contributes to B-Cell Lymphopenia in Active Systemic Lupus Erythematosus. Cell Death Dis (2014) 5(9):e1416. doi: 10.1038/cddis. 2014.375

117. Lee SH, Kwon JY, Kim SY, Jung K, Cho ML. Interferon-Gamma Regulates Inflammatory Cell Death by Targeting Necroptosis in Experimental Autoimmune Arthritis. Sci Rep (2017) 7(1):10133. doi: 10.1038/s41598017-09767-0

118. Weisel K, Berger S, Thorn K, Taylor PC, Peterfy C, Siddall H, et al. A Randomized, Placebo-Controlled Experimental Medicine Study of RIPK1 Inhibitor GSK2982772 in Patients With Moderate to Severe Rheumatoid Arthritis. Arthritis Res Ther (2021) 23(1):85. doi: 10.1186/s13075-02102468-0

119. Mariño G, Niso-Santano M, Baehrecke EH, Kroemer G. Self-Consumption: The Interplay of Autophagy and Apoptosis. Nat Rev Mol Cell Biol (2014) 15 (2):81-94. doi: $10.1038 / \mathrm{nrm} 3735$

120. Lightfoot AP, Nagaraju K, McArdle A, Cooper RG. Understanding the Origin of non-Immune Cell-Mediated Weakness in the Idiopathic Inflammatory Myopathies - Potential Role of ER Stress Pathways. Curr Opin Rheumatol (2015) 27(6):580-5. doi: 10.1097/BOR.000000 0000000212

121. Bedoui S, Herold MJ, Strasser A. Emerging Connectivity of Programmed Cell Death Pathways and its Physiological Implications. Nat Rev Mol Cell Biol (2020) 21(11):678-95. doi: 10.1038/s41580-020-0270-8

122. Sollberger G, Choidas A, Burn GL, Habenberger P, Di Lucrezia R, Kordes S, et al. Gasdermin D Plays a Vital Role in the Generation of Neutrophil 
Extracellular Traps. Sci Immunol (2018) 3(26). doi: 10.1126/sciimmunol. aar6689

123. Orning P, Weng D, Starheim K, Ratner D, Best Z, Lee B, et al. Pathogen Blockade of TAK1 Triggers Caspase-8-Dependent Cleavage of Gasdermin D and Cell Death. Sci (New York NY) (2018) 362(6418):1064-9. doi: 10.1126/ science.aau 2818

124. Newton K, Wickliffe KE, Maltzman A, Dugger DL, Reja R, Zhang Y, et al. Activity of Caspase-8 Determines Plasticity Between Cell Death Pathways. Nature (2019) 575(7784):679-82. doi: 10.1038/s41586-019-1752-8

125. Wang Y, Kanneganti TD. From Pyroptosis, Apoptosis and Necroptosis to PANoptosis: A Mechanistic Compendium of Programmed Cell Death Pathways. Comput Struct Biotechnol J (2021) 19:4641-57. doi: 10.1016/ j.csbj.2021.07.038

126. Karki R, Sharma BR, Tuladhar S, Williams EP, Zalduondo L, Samir P, et al. Synergism of TNF- $\alpha$ and IFN- $\gamma$ Triggers Inflammatory Cell Death, Tissue Damage, and Mortality in SARS-CoV-2 Infection and Cytokine Shock Syndromes. Cell (2021) 184(1):149-68.e17. doi: 10.1016/j.cell.2020.11.025
Conflict of Interest: The authors declare that the research was conducted in the absence of any commercial or financial relationships that could be construed as a potential conflict of interest.

Publisher's Note: All claims expressed in this article are solely those of the authors and do not necessarily represent those of their affiliated organizations, or those of the publisher, the editors and the reviewers. Any product that may be evaluated in this article, or claim that may be made by its manufacturer, is not guaranteed or endorsed by the publisher.

Copyright (c) 2021 Shi, Tang, Zhou, Xu, Zhao, Wu, Wang, Tian, Li and Zeng. This is an open-access article distributed under the terms of the Creative Commons Attribution License (CC BY). The use, distribution or reproduction in other forums is permitted, provided the original author(s) and the copyright owner(s) are credited and that the original publication in this journal is cited, in accordance with accepted academic practice. No use, distribution or reproduction is permitted which does not comply with these terms. 